\title{
Theoretical and experimental study of coupled rocking-swivelling model of guyed mast shaft
}

\author{
Shota Urushadze ${ }^{1, a}$, Miroš Pirner ${ }^{1}$ and Ondřej Fischer ${ }^{1}$ \\ ${ }^{1}$ Institute of Theoretical and Applied Mechanics AS CR, v. v. i, Prosecka 76, 190 00, Prague, Czech Republic
}

\begin{abstract}
Systematic monitoring of rotational vibration (both torsion and swivelling) of guyed mast shafts has been performed in ITAM since 2005. The occurrence of this phenomenon is conditioned by the fact that the guy ropes are attached to the construction of the shaft, i.e. out of its axis. The simple static calculation model serves for making the proof of the occurrence of the torsional moment, affecting the shaft, which is guyed by three ropes. The exact theoretical solution of the real phenomenon assumes the introduction of dynamics of guy ropes, which vibrate in 3D shapes during the shaft's movement along the orbit and it's torsion (swivelling).
\end{abstract}

\section{Introduction}

The problem of rotational movement (or of torsion) of guyed masts during wind-excited vibration has become important in previous Czechoslovakia after the collapse of the mast of the TV transmitter Bohemia-West, Krašov on the January $1^{\text {st }}, 1979$. It was a triangular lattice tubular mast of the height $312 \mathrm{~m}$, fixed at the base in both, bending and torsion, anchored in 4 levels into 3 directions. The highest anchorage was at the height 285 $\mathrm{m}$, its guy was $330 \mathrm{~m}$ long and inclined $60^{\circ}$. On that critical day, in moderate wind, some of the longest guys started to sway with the planes of their sags, synchronizing step by step their rhythm with the torsional vibration of the whole shaft, and this stationary movement lasted for several hours. The transversal amplitudes of the long guys, as well as the transversal forces in the suspension points, were considerable, exciting the shaft torsion in their upper hangers and heavy transversal loading on the lower ones. These were realized as a well designed flat steel tie, but even those, after many times repeated bending perpendicular to its plane and probably over the yield point, could not resist. The tie loosed, the anchorage plucked off, the highest span with the cantilever $(101 \mathrm{~m})$ fell down, fortunately without other damages. The rest of the mast had to be, of course, demolished.

The described collapse has revealed that such a classical structure like the mast had not been fixed perfectly in space - one of its degrees of freedom, namely the rotation about the vertical axis (the axis of the shaft) remains unbound. The shaft was usually supported on a hinge and the guys were arranged so that they intersect the shaft axis and are not able to resist to moments (eccentric loadings) in horizontal plane. But such loadings usually do no occur on masts, thus it was not necessary to

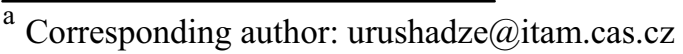

compensate this degree of freedom and small (infinitesimal) shaft rotations were tolerated. If nevertheless a special mast should resist to eccentric loads (e.g. wind loads on antennae or pick-up elements on long cantilevers outside the shaft).

The statics of guyed masts was sufficiently elaborated as early as the first half of the 20th century, also with respect to the nonlinearity of the effect of ropes [1].

The basis for the dynamics of guyed masts was published by Koloušek [5], with the use of his deformation method. Since then the field of dynamics of guyed masts has extended by the knowledge of the effects of nonlinear phenomena, parametric resonance and self-excitation. Out of these, let us state at least $[6,7]$.

The theoretical analysis of the mast should always be corrected on the basis of monitoring of the real structure. From the measuring of the dynamic response of masts or of their models it was known that the resulting movement of the shaft in ground plan appears as an ellipse, whose major axis forms an angle smaller than $90^{\circ}$ with the direction of the wind. Usually low intensity of turbulence and smooth surface of the shaft are conditions for the regularity and intensity of the vortex shedding. High intensity of turbulence disturbs the regularity of the shedding and thus also the cross-wind direction excitation and then the ellipse becomes more a circle [2 - 4].

\section{Torsion or swivelling of the mast shaft}

The shifting from zero position will result in changes of the forces in the ropes and moments in the points of connection to the shaft, which are out of the axis of the shaft. If the shaft is guyed by three ropes, there are 6 points on the elliptical orbit, in which the sum of the moments from the eccentric connection of the ropes is 
zero, and thus also the swivelling is zero (see Fig. 1). These points delimit the domains with positive or negative rotation of the shaft. The zero points may lie close to each other; in such a case the domains prevail with their size at the apexes of the ellipse. If the ellipse degenerates into a line, there are two domains of rotation which differ in the plus/minus sign.

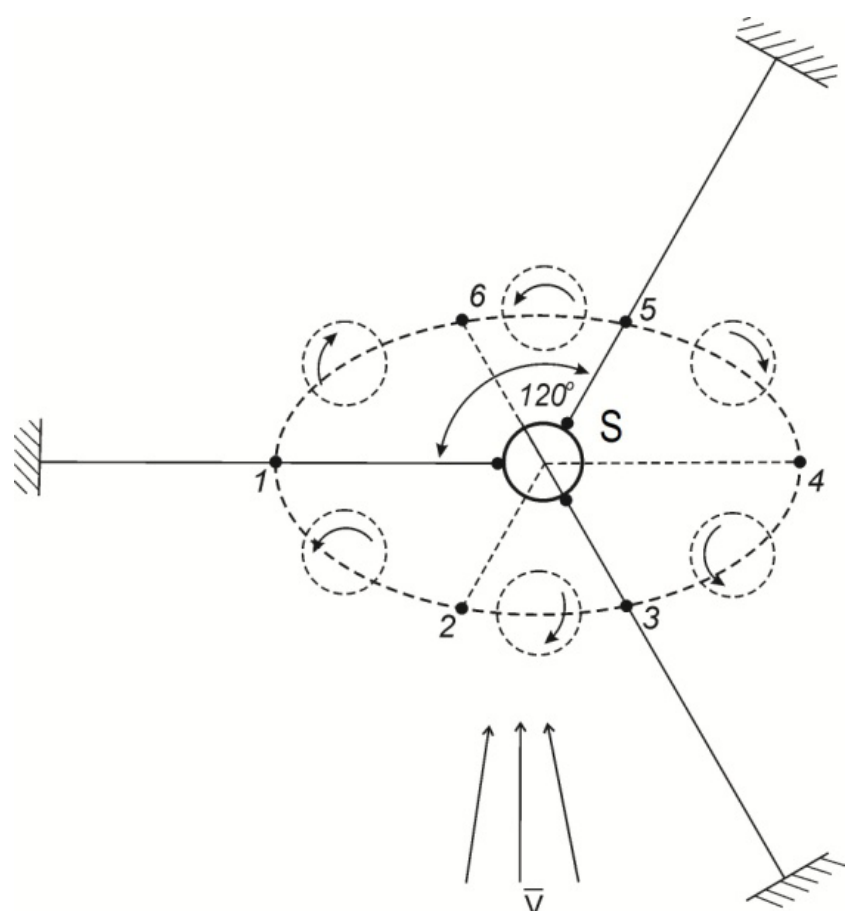

Figure 1. Rotation of the shaft owing to the eccentricity of the ropes.

The frequency of torsion or swivelling of the shaft depends on the position of the zero points on the ellipse (see Fig. 1): if the zero points are far enough from each other, the torsion of the shaft is governed by these 6 domains of moments and the frequency of swivelling $f_{\text {tor }}$ is

$$
f_{\text {tor }}=4 f_{b}
$$

where $f_{b}$ is the frequency of bending

If points (see Fig. 1) 2 and 3 merge into one, and so do points 5 and 6 , then:

$$
f_{\text {tor }}=f_{b}
$$

The proof of the occurrence of moments which swivel (torsion) the shaft will be made using a simple calculation model, in which we take into account only static effects. The ropes are in a horizontal plane, without sag. Fig. 2 shows the ground plan of a shaft of triangular cross section, guyed in one level by three ropes (1., 2. and 3.).

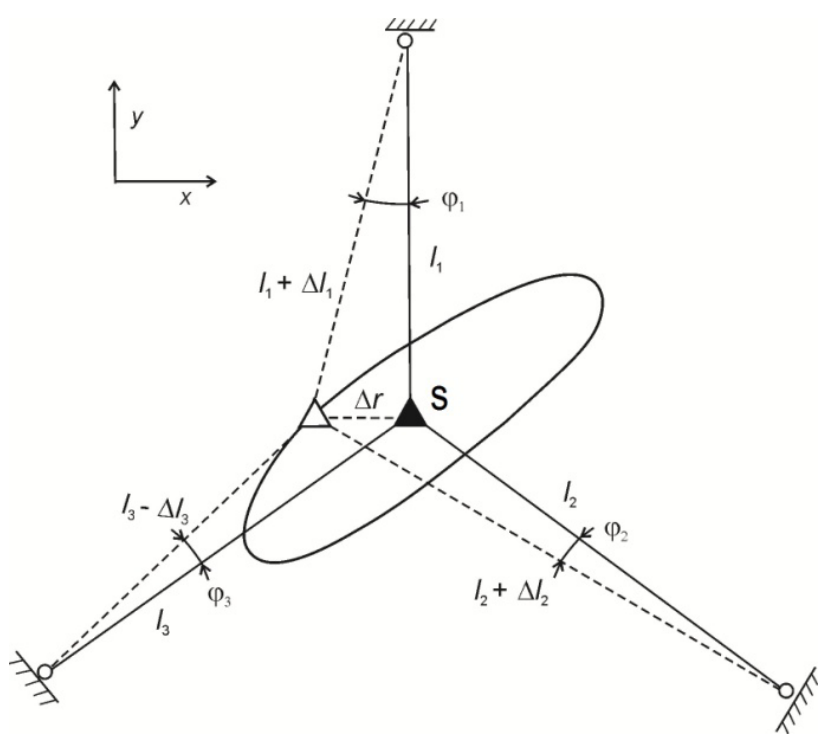

Figure 2. Deriving the length strain of the ropes.

When moving the shaft by $\Delta r$ in the direction of $\mathrm{X}$ axis, the ropes 1 . and 2 . of a length of $l_{1}$ and $l_{2}$ will lengthen by

$$
\begin{aligned}
& \Delta l_{1}=\sqrt{l_{1}^{2}+\Delta r^{2}}-l_{1} \\
& \Delta l_{2}=l_{2}\left(\cos \varphi_{2}-1\right)+\Delta r \cdot \cos \left(30^{\circ}-\varphi_{2}\right) \\
& \text { and the 3rd rope will shorten by } \\
& \Delta l_{3}=\frac{l_{3}-\Delta r \cdot \cos 30^{\circ}}{\cos \varphi_{3}}-l_{3}
\end{aligned}
$$

where $l_{i}$ are the lengths of rope

When $\Delta \mathrm{r}$ is $\|$ the axis $\mathrm{X}$ then $\Delta \mathrm{y}=0, \Delta \mathrm{x}=\Delta \mathrm{r}$,

$$
\begin{aligned}
& \cos \varphi_{1}=\frac{l_{1}}{l_{1}+\Delta l_{1}} \\
& k_{i}=\frac{A \cdot E}{l_{i}} \\
& \Delta F_{i}=k_{i} \cdot \Delta l_{i}
\end{aligned}
$$

Using the length transformations of the ropes $\Delta l_{i}$ and the chosen spring constant $k_{i}$ of the rope we will determine the increments of forces in the ropes $\Delta F_{i}$, whose components on the arms $r_{s i}$ create the resulting moment (see Figure 3)

$$
M=\sum_{1}^{3} \Delta F_{i} \cdot r_{s i}
$$




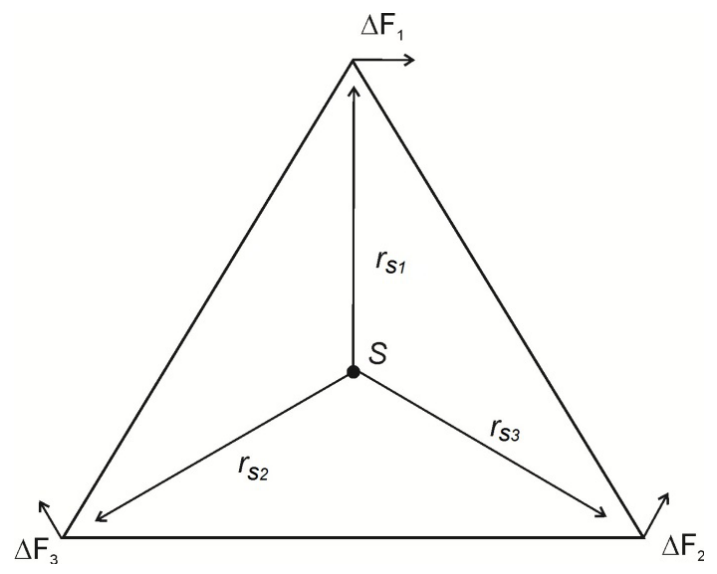

Figure 3. Components of forces and their moment arms to the rotation axis.

\section{Monitoring of torsion (swivelling) on real structures}

The torsion of the mast shaft was monitored on three masts [1], [2], [7]. Two other guyed masts were monitored in the year 2011. Lets us see results. The first one is on the Fig. 4. The movements of the shaft were monitored at the height of $124.88 \mathrm{~m}$ by means of two accelerometers ENDEVCO, type 86, the signals of which could have been mutually added or subtracted (see Fig. 5).
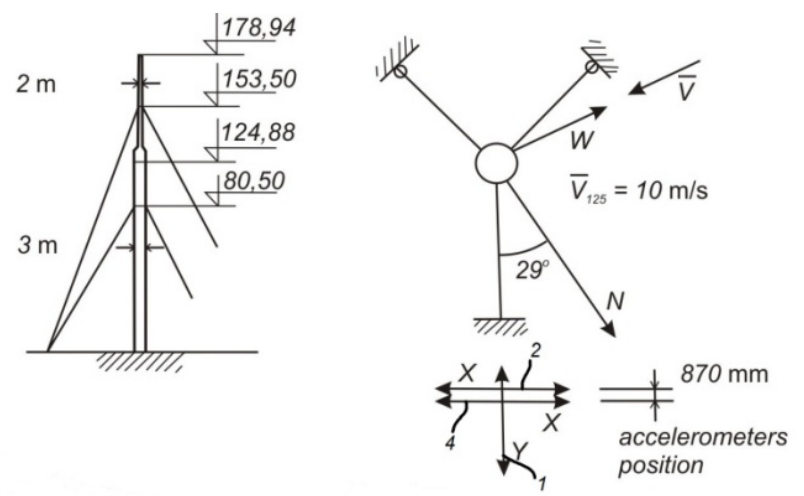

Figure 4. The first guyed mast.

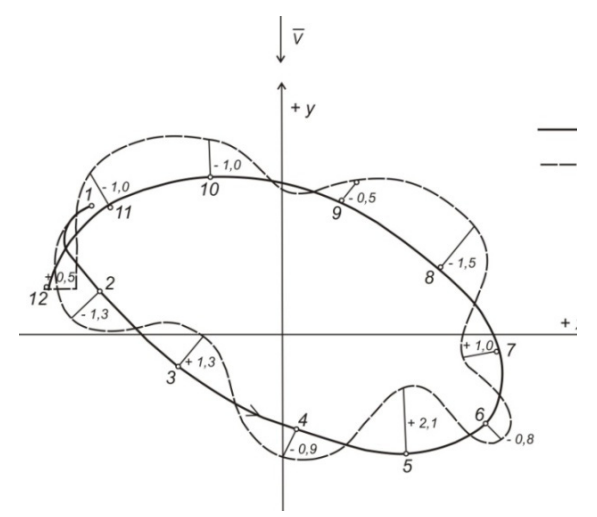

Figure 5. Example of the mast torsion and rocking.

\section{Monitoring of Torsion (Swivelling) on a Mast-Shaft Model}

An experimental mast-shaft model of $15 \mathrm{~m}$ height guyed in 3 directions was used for the more detailed study of its rotational motion. The excitation was realized by transversal auxiliary rope drawn by harmonic human force in resonance. The displacement of the shaft top results in translation caused by the guy force and the rotation, caused by the eccentricities of the guy-ropes, attached out of the shaft axis. The resulting movement of the shaft support is an elliptical orbit. The shaft of our experimental mast was equipped in two levels with accelerometers for registration of horizontal $x, y$ motions. The two $x, y$ signals in two levels were monitored and analysed (see Fig. 6).

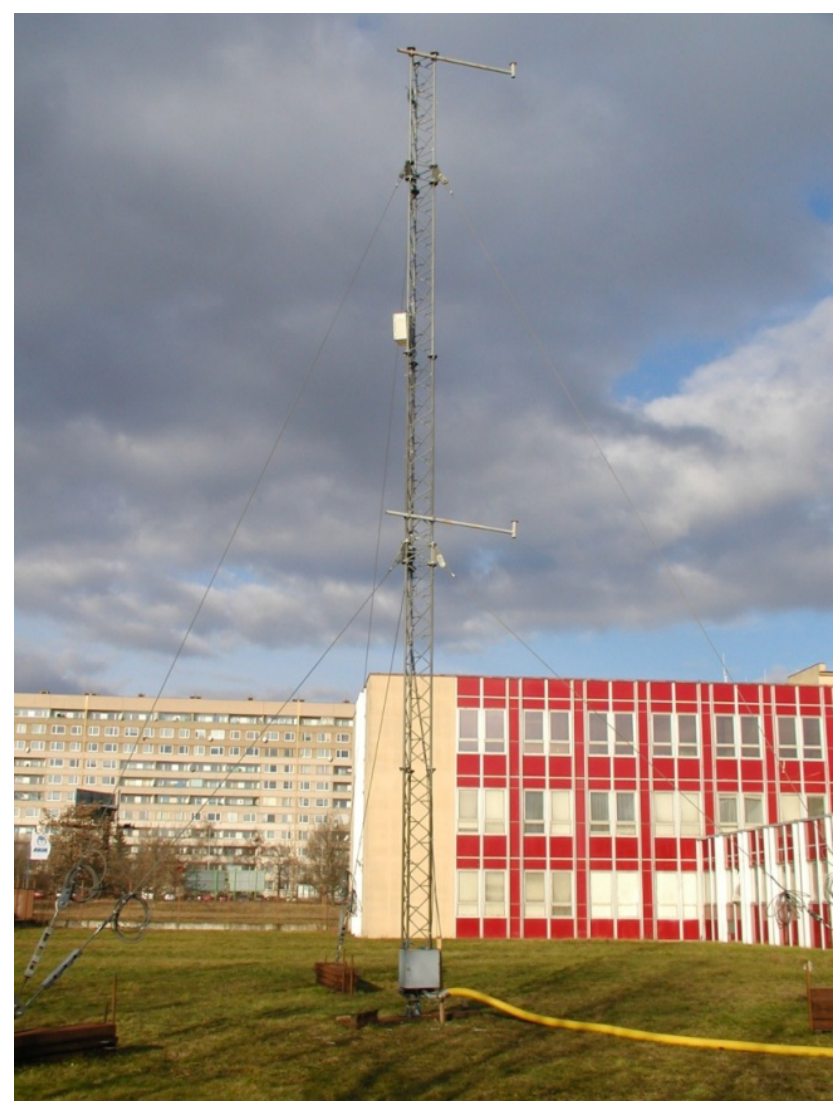

Figure 6. View of the mast model.

Fig. 7 shows the records of the plotter of the orbit and the course of swivelling of the shaft relative to it. ${ }^{\text {a }}$

The movements of the shaft were monitored at a height of $6.7 \mathrm{~m}$ and $13 \mathrm{~m}$ by means of two accelerometers Endevco, type 86, the signals of which could have been mutually added or subtracted. The distance of the parallel axes from the accelerometers was $525 \mathrm{~mm}$. An example of analysis is in Fig. 8. The agreement of the frequency of flexural vibration with the frequency of torsional vibration is obvious; other ratios of frequencies did not occur.

\footnotetext{
${ }^{a}$ The deviations from ideal elliptical orbits and the courses of swivelling are caused for example by imperfect smoothness of the air flow.
} 


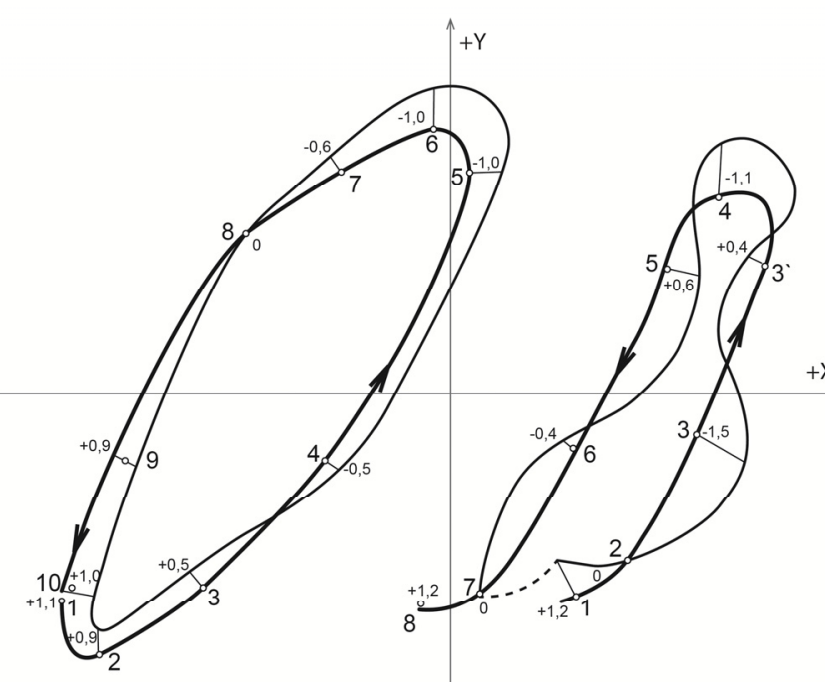

Figure. 7. Two examples of mast-top trajectories with different rocking - torsion ratios. The thick line - orbit, the distance between thick and thin line - value of the torsion.
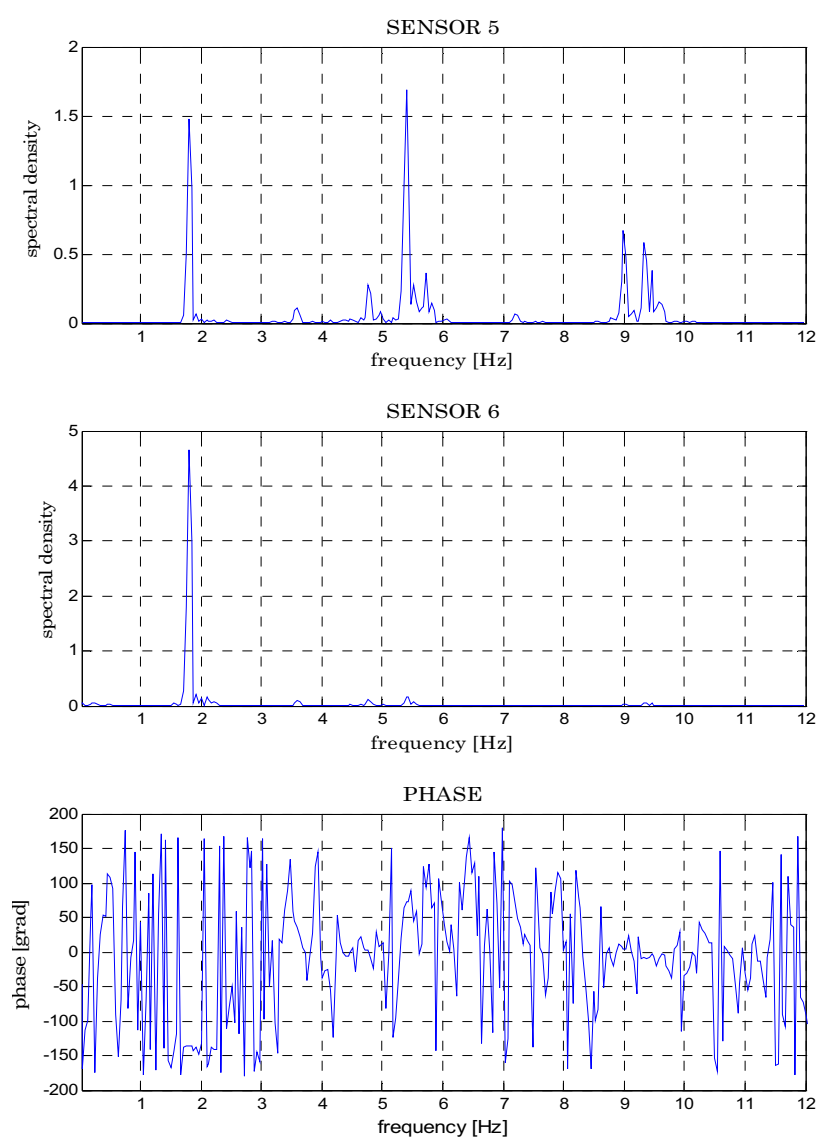

Figure 8. Power spectral densities and the phase shift.

\section{Monitoring of swivelling on the small model}

In more detail and more stable aerodynamic conditions was the phenomenon of swivelling of the mast shaft examined on a simple model. The shaft was a tube from hardened PVC, of an outer diameter of $75 \mathrm{~mm}$, supported by a hinge at the bottom and guyed by three wires in one level.

The flexural rigidity of the shaft is not modelled; the bending is substituted by its rocking displacement. That is why there are no higher modes of rocking motion and the orbit is always close to an ellipse.

The top of the shaft is outside the flow stream of the tunnel, therefore the shaft could be equipped with a horizontal arm with two accelerometers attached on its ends; the distance between the accelerometers is $165 \mathrm{~mm}$ - see Fig. 9. Accelerometers 1 and 2 measure the horizontal motion in the direction perpendicular to the horizontal arm. Besides the two accelerometers on the ends of the horizontal arm there is also a third accelerometer at the upper end of the shaft, which follows the motions perpendicular to the direction of the above pair of accelerometers.

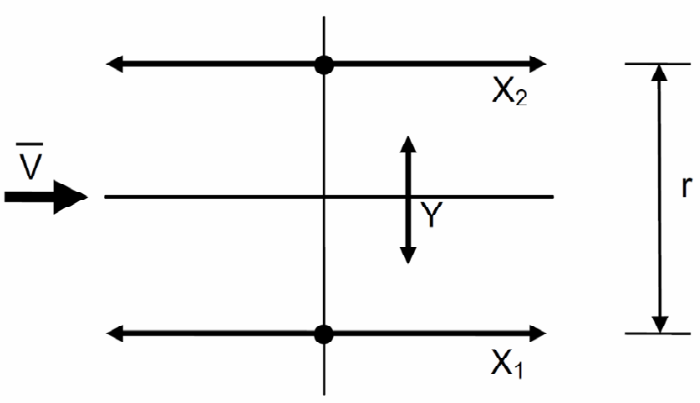

Figure 9. The plan positions of the sensors $\mathrm{X}_{1}, \mathrm{X}_{2}$, and $\mathrm{Y}$. The distance $\mathrm{r}=380 \mathrm{~mm}$.

\section{Monitoring of Swivelling on a Small Model}

The torsion was verified in a wind tunnel and by deformations were determined. The experiments has been performed in the new aerodynamic tunnel (ITAM Telč). Wind tunnel section size $2700 \times 2500 \mathrm{~mm}$ enabled experiment with model shaft up to $1500 \mathrm{~mm}$ high, anchored by three ropes at a height of $1000 \mathrm{~mm}$. The mast model was adjusted within the admissible limits by means of stressing of the wires and increasing the mass concentrated on the top of the shaft. The model-laws, giving the conditions for geometrical, force and Reynold's numbers similitudes, were not respected, as it generally is in the cases in model analyses of guyed masts.

The top end of the shaft was equipped with a horizontal arm with two accelerometers attached on its ends; the distance between the accelerometers is $380 \mathrm{~mm}$. Accelerometers 1 and 2 measure the motion in the direction perpendicular to the horizontal arm. Besides the two accelerometers on the horizontal arm there is also the third accelerometer at the upper end of the shaft, which senses the motions perpendicular to the direction of the above pair of accelerometers - see Fig. 9.

On the Fig. 10 there is the model in wind tunnel ITAM - Telč. 


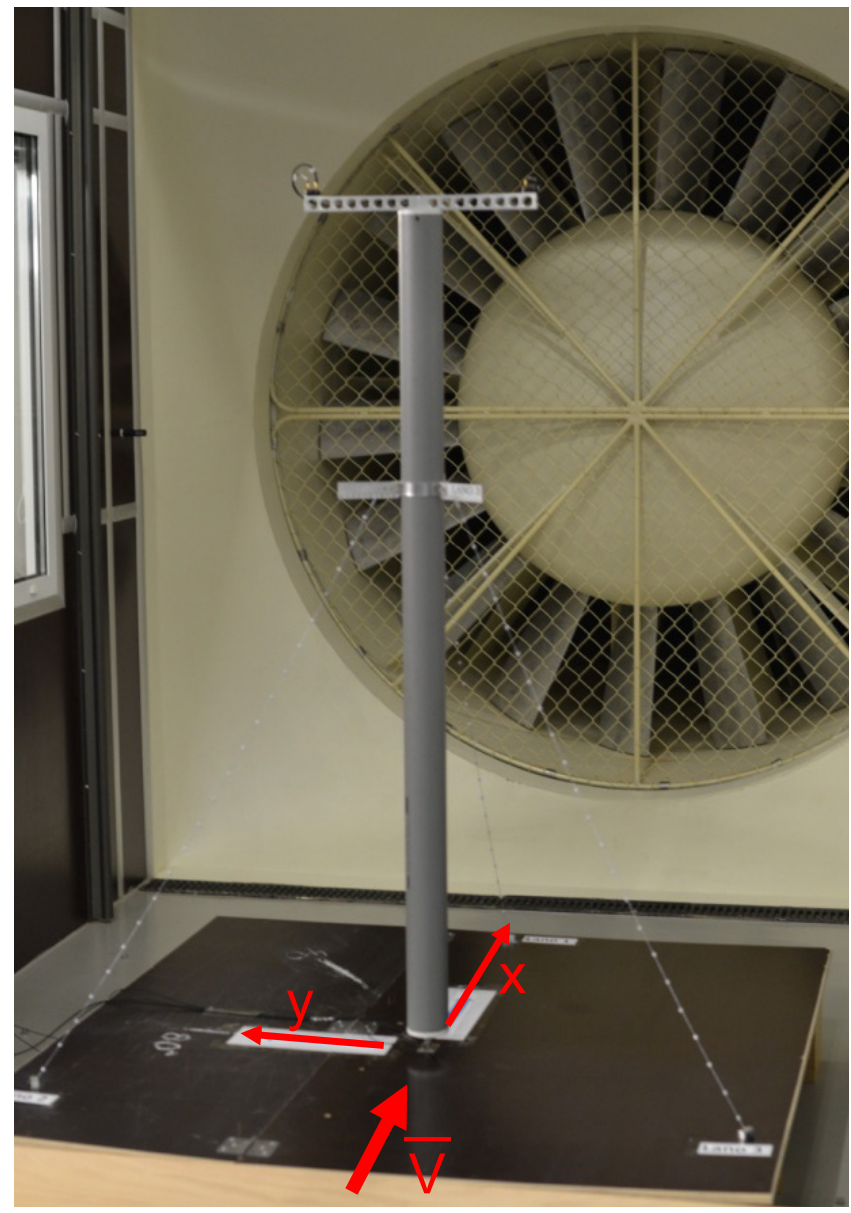

Figure 10. The model of the guyed mast.

The mast model was adjusted within the admissible limits by means of stressing of the wires and increasing of the mass concentrated on the top of the shaft.

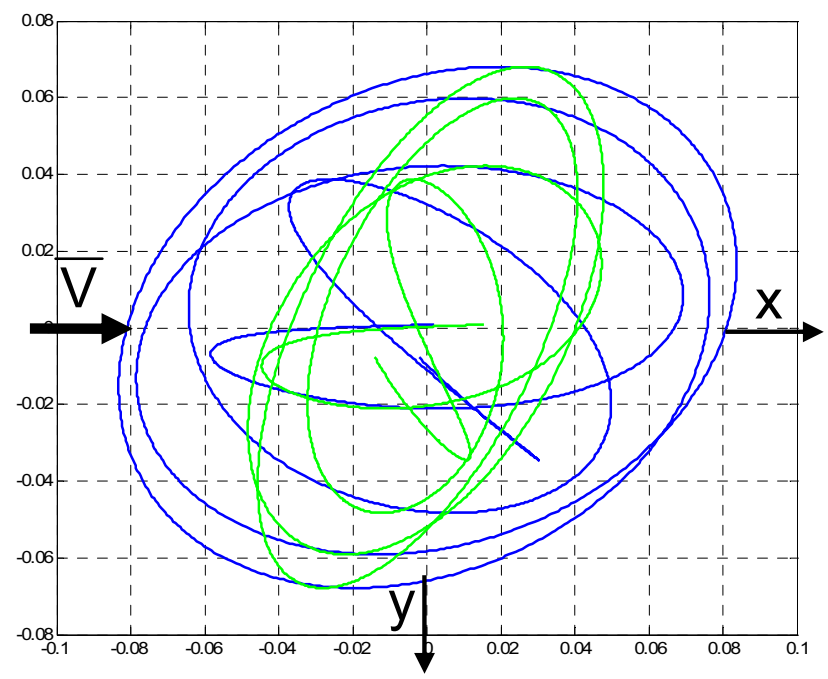

Figure 11a. Examples of the superposition of the shaft motions (Frequency range: $0.8 \div 1.2 \mathrm{~Hz}$, guy force: $250 \mathrm{~N}$, eccentricity: $4^{\text {th }}$ hole, $\overline{\mathrm{V}}=0.55 \mathrm{~m} / \mathrm{s}$ ).

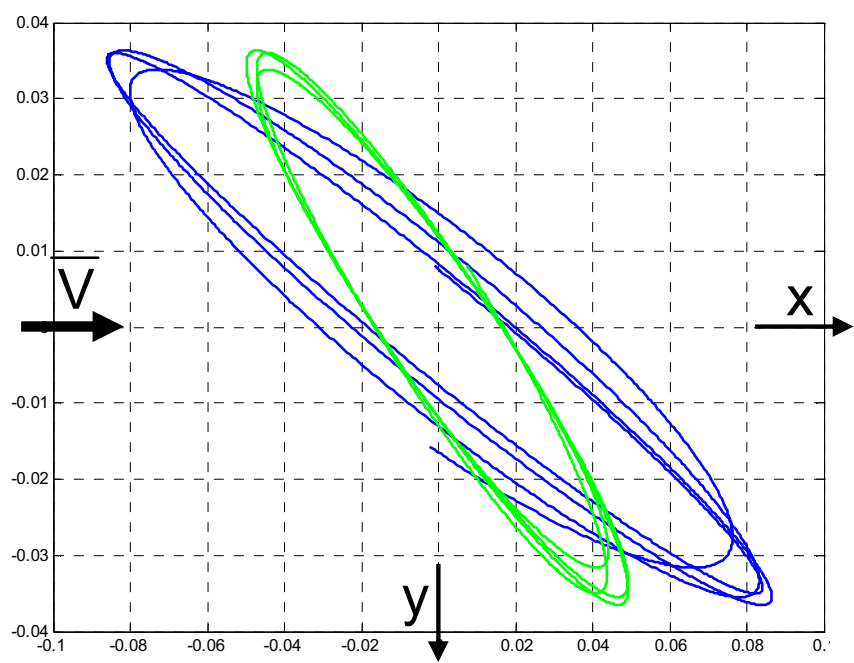

Figure 11b. Examples of the superposition of the shaft motions (Frequency range: $0.6 \div 0.8 \mathrm{~Hz}$, guy force: $250 \mathrm{~N}$, eccentricity: $7^{\text {th }}$ hole, $\overline{\mathrm{V}}=0.65 \mathrm{~m} / \mathrm{s}$ ).

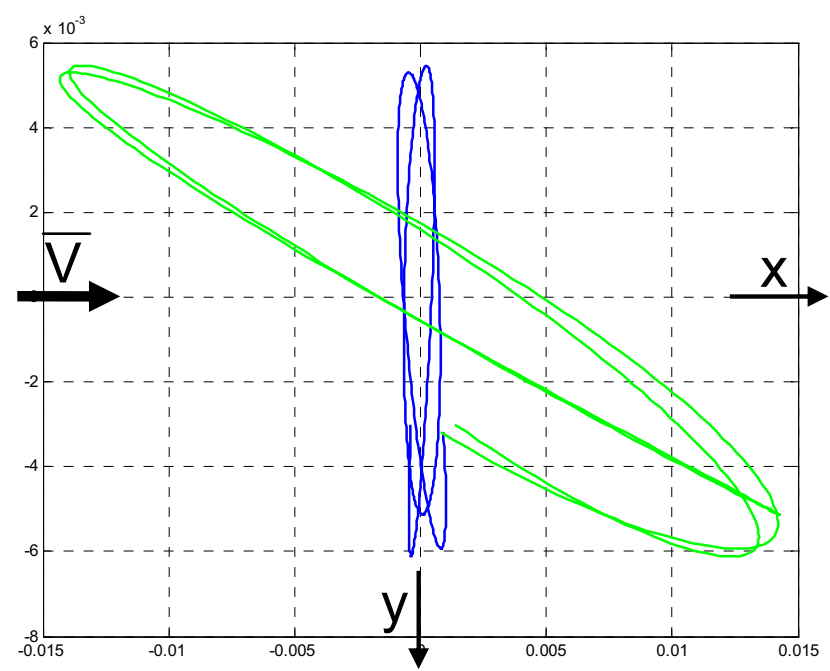

Figure 11c. Examples of the superposition of the shaft motions (Frequency range: $2.8 \div 3.2 \mathrm{~Hz}$, guy force: $250 \mathrm{~N}$, eccentricity: $10^{\text {th }}$ hole, $\left.\overline{\mathrm{V}}=0.65 \mathrm{~m} / \mathrm{s}\right)$.

Fig. 11 shows the records of the orbit and swivelling of the shaft relative to it. The eccentricity of the attachments of the guys to the shaft was one of the parameters of the model; see Fig. 12.

In Figs 11a, 11b, 11c the responses of the shaft top have been given, viz. their filtrated frequency of the response, of the wind-stream velocity and of the guy force. The blue line - the response $\left(\mathrm{x}_{1}-\mathrm{x}_{2}\right)$ with respekt to $\mathrm{Y}$ - axis; the green one - the response $\left(\mathrm{x}_{1}+\mathrm{x}_{2}\right) / 2$ to the axis $Y$ too. In all three cases the frequency of shaft rotation was the same as that of the rocking. 


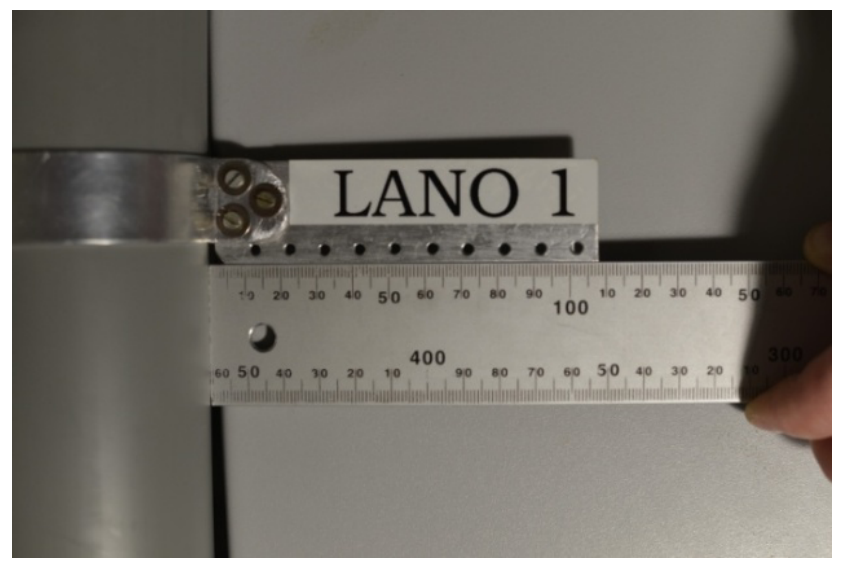

Figure 12. Possibility to change the distance of guy rope attachment to the shaft axis.

From the measurements, the dependence of the response on the stream velocity can be approximated as shown in Fig. 13.

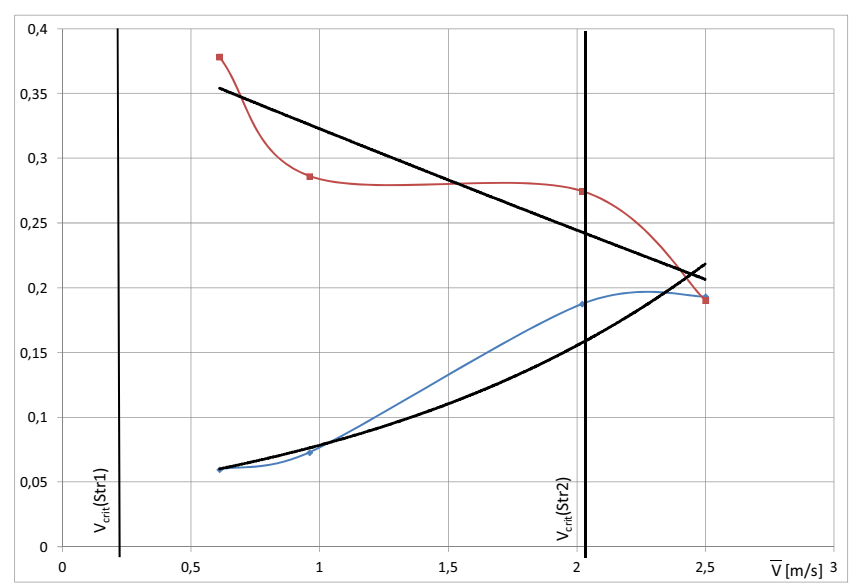

Figure 13. Dependence of the response on the stream velocity $\overline{\mathrm{V}}$.

Red: RMS y, Blue: RMS $\left(\mathrm{x}_{1}+\mathrm{x}_{2}\right) / 2$, guy force: $2,5 \mathrm{~N}$, Eccentricity: $7^{\text {th }}$ hole,

$\mathrm{V}_{\text {crit }}$ wind speed for $1^{\text {st }}$ and $2^{\text {nd }}$ Strouhal frequency

\section{Conclusion}

The existence of torsion (swivelling) takes only a short time, in which the orbit of the shaft is near the ellipse.

The torsion (swivelling) of the shaft is very small and insignificant for the stress of the shaft. But it is important for the quality of broadcasted (for example) telephone signal in case of longer transmission distance.

Our measurements, both, on models in the tunnels, and as well as those in situ, have confirmed the existence of coupling between the translational (bending, rocking) and rotational (torsion, swivelling) motions of the shaft of guyed masts in wind, depending on different parameters, like anchoring guy force, wind velocity, guy to shaft eccentricity. We suppose to continue similar experiments, especially on models with zero eccentricity of the anchoring guys

\section{Acknowledgment}

The kind support of the Czech Science Foundation Project No. GC13-34405J and of the RVO 68378297 institutional support are gratefully acknowledged.

\section{References}

1. Bleich, F., Stahlhochbauten, Abschn., Leitunmaste und Funktürme. Berlin. (1933)

2. Fischer,O., Pirner, M., Dynamics of guyed masts, Study 2/87, Academia, Prague, (In Czech) (1987)

3. Fischer, O., Náprstek, J., Pirner, M., Dynamic response of guyed masts to wind action. In Proceedings Congress IASS, Madrid. (1979)

4. Koloušek, V. et al., Wind effects on civil engineering structures, Academia-Elsevier, Prague. (1983)

5. Koloušek,V., Solution statique et dynamique des pylones d'antenne haubanés, Mem. de l'AIPC, VIII, Zürich. (1947)

6. Peil, U., Collapse behaviour of guyed masts under gales and guy-rupture, in: Proc. on 2nd EECWE, Prague (1998)

7. Sparling, B.F., Comparison of frequency and time domain analyses for guyed masts in turbulent winds, IASS, Group 4 on Masts and Towers, Oslo, Norway, (2001) 